\title{
Pengembangan sistem kearsipan dan administrasi gaji elektronik (SIPAMIGA) berbasis website dinamis di PT. Subur Jaya Prima Kabupaten Tuban
}

\author{
Faridatun Nafisah, Heri Pratikto* \\ Universitas Negeri Malang, Jl. Semarang No. 5 Malang, Jawa Timur, Indonesia \\ *Penulis korespondensi, Surel: heri.pratikto.fe@um.ac.id
}

Paper received: 1-4-2021; revised: 22-4-2021; accepted: 29-4-2021

\begin{abstract}
Abstrak
Saat ini teknologi dimanfaatkan oleh Perusahaan sebagai salah satu sarana penunjang kinerja operasional dan kegiatan perkantoran. salah satunya yaitu di bidang kearsipan. Berkaitan dengan hal tersebut, maka diperlukan adanya pengembangan lebih lanjut pada sistem kearsipan di perusahaan dengan memanfaatkan teknologi yang sudah ada dan sedang berkembang saat ini. Oleh karena itu, penelitian ini bertujuan untuk menghasilkan produk sistem kearsipan dan Administrasi gaji elektronik berbasis website dinamis yang layak dan efektif untuk digunakan berdasarkan hasil validasi Ahli Materi dan Ahli Media serta Pengguna sesuai dengan kebutuhan. produk sistem kearsipan gaji yang dikembangkan dapat menjadi alternatif pilihan bagi perusahaan dalam meminimalisir kesalahan yang terjadi pada proses kearsipan administrasi gaji. Penelitian dan pengembangan ini menggunakan model Research and Development Borg and Gall yang telah dimodifikasi. Teknik analisis data yang digunakan adalah teknik analisis deskriptif dan teknik deskriptif persentase. Hasil penelitian dan pengembangan ini adalah menghasilkan sistem kearsipan dan administrasi gaji elektronik (SIPAMIGA) berbasis website dinamis yang dinyatakan sangat valid, layak dan efektif untuk digunakan berdasarkan penilaian ahli media, ahli materi, dan 7 pengguna uji coba kelompok kecil. Sehingga dapat disimpulkan bahwa SIPAMIGA layak dan efektif digunakan sebagai sistem kearsipan administrasi gaji.
\end{abstract}

Kata kunci: penelitian dan pengembangan; sistem kearsipan dan administrasi gaji elektronik; website dinamis

\section{Pendahuluan}

Selama beberapa tahun terakhir, pesatnya perkembangan teknologi informasi dan komunikasi dimanfaatkan oleh perusahaan untuk menunjang kegiatan operasional dan kegiatan perkantoran (Holgersson \& Aaboen, 2019), (Liu \& Huang, 2020), (Shirai \& Kiritani, 2021). Salah satu pemanfaatan teknologi di kegiatan perkantoran yaitu di bidang kearsipan berupa pengelolaan arsip berbasis elektronik (Jervis \& Masoodian, 2014), (Kaneko, 2018), (Sun, 2020). teknologi mengubah kegiatan kearsipan yang dulu dilakukan secara konvensional menjadi elektronik atau otomatis (Engelman, Enkvist, \& Pettersson, 2019), (Zheng, Wang, Zhang, Wu, \& Yang, 2020). Pengelolaan arsip berbasis elektronik penting dilakukan oleh perusahaan karena arsip merupakan pusat ingatan bagi perusahaan (Putra \& Nelisa, 2020). Selain itu, Arsip merupakan salah satu sumber data dari segala kegiatan manajemen yang dimiliki oleh perusahaan (Lee, Aydin, Choi, Lekhavat, \& Irani, 2018), (Sievers, Reil, Rimbeck, Stumpf-Wollersheim, \& Leyer, 2021). Salah satu arsip yang perlu diarsipkan yaitu terkait administrasi gaji.

Sistem kearsipan elektronik sendiri memiliki banyak manfaat (Jacobs et al., 2019), (Barter \& Cooper, 2021), (Jedwab, Chalmers, Dobroff, \& Redley, 2019). Kearsipan elektronik membantu mempercepat penemuan kembali arsip (Engelman et al., 2019). Kearsipan

This work is licensed under a Creative Commons Attribution-ShareAlike 4.0 International License. 
elektronik juga mampu meningkatkan keamanan arsip lebih terjaga (Grahl et al., 2017),(Filchev, Pashova, Kolev, \& Frye, 2020), (Usman \& Qamar, 2020). Beberapa penelitian sebelumnya bahkan telah membuktikan bahwa sistem kearsipan mampu meminimalisir penggunaan kertas dan ruang kantor (Polat \& Alkan, 2018). Sehingga kearsipan elektronik meminimalisir biaya yang dikeluarkan oleh perusahaan (Santipantakis et al., 2020). Selain itu kearsipan elektronik dianggap mampu meningkatkan hasil pekerjaan menjadi lebih efektif dan terstruktur (Artamonov, Ionkina, Tretyakov, \& Timofeev, 2018), (Ayaz \& Yanartaş, 2020), (Casey, Turner, Edwards, \& Williams, 2020).

Beberapa penelitian bahkan telah mengembangkan sistem kearsipan yang memuat proses pengisian sampai dengan penyimpanan arsip (Simangunsong, 2018), (Perdanakusuma, Puspitasari, \& Saputra, 2020). selain itu, telah dikembangkan sistem administrasi gaji yang memuat proses pengajuan gaji, cetak slip gaji sampai dengan laporan penggajian (Bagir \& Rahmadian, 2016), (Villarama, 2017), (Mulyani, Sidik, \& Sari, 2020). sistem yang dikembangkan berbentuk website dengan tujuan agar sistem dapat diakses oleh kedua pihak yaitu pihak perusahaan dan karyawan (Klapita, 2021). Berdasarkan penelitian-penelitian tersebut dapat disimpulkan bahwa pengembangan sistem kearsipan berbasis website dapat menjadi terobosan bagi perusahaan dalam melakukan kegiatan kearsipan administrasi gaji yang layak dan efektif untuk digunakan.

Disamping itu, berdasarkan hasil wawancara dengan Manajer Keuangan dan Arsiparis di PT. Subur Jaya Prima bahwasanya perusahaan masih menggunakan sistem kearsipan manual, karyawan masih kesulitan mencari kembali arsip yang dibutuhkan, seringnya kehilangan arsip karena arsip tersebut lupa bahkan hilang sebelum di arsipkan. Pada kegiatan administrasi gaji perusahaan masih menggunakan alat manual yaitu kalkulator sebagai alat hitung dan seringnya terjadinya human error berupa kesalahan penulisan pada slip gaji yang tentunya apabila hal tersebut berlanjut maka akan merugikan pihak karyawan maupun pihak perusahaan. Dari masalah tersebut Peneliti berinovasi membuat sebuah sistem kearsipan gaji untuk membantu permasalahan yang dihadapi perusahaan dengan memanfaatkan teknologi informasi secara maksimal. Peneliti berinovasi membuat sebuah sistem kearsipan gaji yang bisa diakses pada handphone atau laptop dimana saja dan kapan saja. Aplikasi ini berisikan proses kegiatan kearsipan administrasi gaji mulai dari pencatatan sampai dengan penyimpanan serta memuat proses administrasi gaji mulai dari presensi, penulisan sampai pencetakan slip gaji dan pinjaman karyawan yang dapat diakses oleh pihak karyawan maupun pihak perusahaan sebagai bagian dari proses kegiatan pengawasan.

\section{Metode}

Penelitian ini menggunakan model Research and Development Borg and Gall yang telah dimodifikasi menjadi delapan langkah untuk mempersingkat waktu dan meminimalisir biaya (Mastumasari et al., 2017). Selain itu, peneliti juga merasa bahwa tujuan penelitian yaitu untuk menghasilkan produk, mengetahui kelayakan produk berdasarkan validasi ahli materi dan media, dan mengetahui keefektifan produk berdasarkan hasil uji coba pengguna, sudah dapat tercapai di tahap kedelapan. 


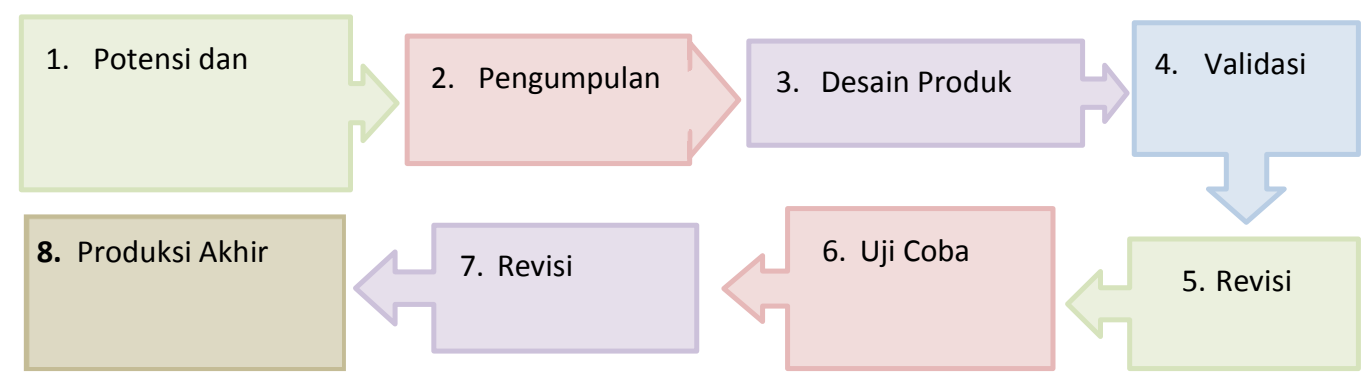

Gambar 1. langkah-langkah penelitian

Langkah pertama, peneliti mengumpulkan informasi terkait permasalahan yang terjadi di kantor PT. Subur Jaya Prima melalui wawancara dan observasi. Langkah kedua, peneliti merancang produk sistem kearsipan gaji yang akan dikembangkan dan dapat menjadi solusi atas permasalahan yang ditemukan pada langkah pengumpulan informasi awal. Langkah ketiga, peneliti mulai membuat sistem sesuai rancangan yang telah ditentukan pada langkah sebelumnya. Langkah keempat, sistem yang dihasilkan peneliti diuji kelayakan oleh para validator, yakni satu ahli media dan satu ahli materi. Langkah kelima, produk yang telah divalidasi direvisi berdasarkan masukan serta saran baik secara lisan maupun tulisan yang tertera pada lembar angket penilaian ahli materi dan ahli media. Langkah keenam, produk yang telah direvisi diujicobakan pada 7 karyawan PT. Subur Jaya Prima yang terdiri dari pengguna sebagai administrator dan pengguna sebagai karyawan berdasarkan kebutuhan.. Langkah ketujuh, produk yang telah diujicobakan pada kelompok kecil direvisi sesuai masukan-masukan karyawan baik secara lisan maupun tulisan yang tertera pada lembar hasil angket uji coba kelompok kecil. Langkah kedelapan, Produk yang telah melewati uji coba menjadi produk akhir dalam penelitian ini.

Data yang dihasilkan pada penelitian ini meliputi data kualitatif dan data kuantitatif, dimana data kualitatif didapatkan melalui penarikan kesimpulan berdasarkan pendapat secara umum, saran, dan kritik dari ahli materi, ahli media, dan 7 karyawan uji coba kelompok kecil yang dianalisis menggunakan teknik analisis deskriptif. Sedangkan data kuantitatif terdiri dari data hasil validasi ahli materi, data hasil validasi ahli media, dan data hasil uji coba kelompok kecil yang dianalisis menggunakan teknik deskriptif persentase yang hasilnya menunjukkan tingkat kelayakan dan keefektifan SIPAMIGA.

\section{Hasil dan Pembahasan}

Produk yang dihasilkan dalam penelitian dan pengembangan ini adalah sistem kearsipan gaji berbasis website dinamis yang layak dan efektif untuk digunakan karyawan PT. Subur Jaya Prima dengan nama SIPAMIGA. SIPAMIGA dapat digunakan oleh dua pengguna yaitu pengguna sebagai administrator dan pengguna sebagai karyawan. SIPAMIGA secara garis besar terdiri dari tombol menu yang dijelaskan melalui Gambar 2,3, dan 4 sebagai berikut ini: 
Jurnal Ekonomi, Bisnis dan Pendidikan, 1(4), 2021, 405-412

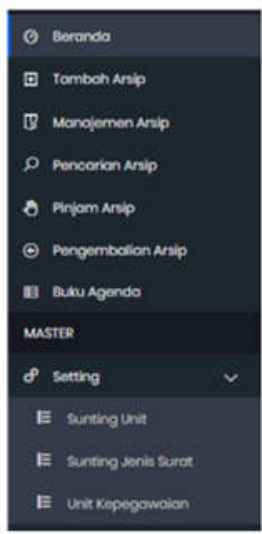

\begin{tabular}{|l|}
\hline Berisi informasi berbentuk statistika terkait jumlah arsip yang dimiliki \\
\hline Menu untuk menambahkan arsip yang akan disimpan \\
\hline kumpulan dari beberapa arsip dan memuat sekilas informasi arsip \\
\hline Menu yang berfungsi untuk mencari kembali arsip \\
\hline Menu yang berfungsi untuk meminjam sebuah arsip \\
\hline Menu yang berfungsi untuk mengembalikan arsip yang dipinjam \\
\hline $\begin{array}{l}\text { Menu yang berfungsi untuk melihat pergerakan penyimpanan arsip } \\
\text { berdasarkan tanggal penyimpanan }\end{array}$ \\
\hline $\begin{array}{l}\text { Menu yang berfungsi untuk mengatur unit arsip, jenis arsip, dan } \\
\text { masalah pokok arsip yang dimiliki }\end{array}$ \\
\hline
\end{tabular}

\section{Gambar 2. Menu Kearsipan dalam Website Administrator}

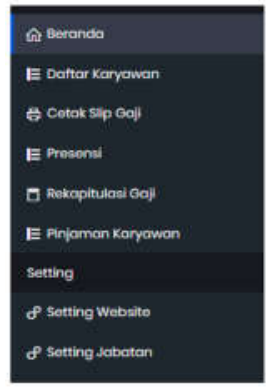

Berisi statistika informasi presensi 5 hari terakhir

informasi seluruh karyawan yang dimiliki oleh perusahaan

berfungsi mencetak slip gaji karyawan

Kumpulan rekap presensi karyawan berdasarkan periode tertentu

kumpulan rekap gaji yang dimiliki oleh karyawan

Menu untuk mengkonfirmasi permintaan pinjaman karyawan

Menu Yang berfungsi untuk mengatur website dan jabatan yang

dimiliki seorang karyawan

\section{Gambar 3. Menu Administrasi Gaji dalam Website Administrator}

\begin{tabular}{|l|l|}
\hline $\begin{array}{l}\text { Q Beranda } \\
\text { R Profle }\end{array}$ & berisi profil sekilas dari karyawan dan statistika presensi karyawan \\
\hline $\begin{array}{l}\text { E Presenal } \\
\text { E Plnjaman Karyawan } \\
\text { b Petisikan infoosiooj }\end{array}$ & berisikan rekapan daftar hadir karyawan setiap harinya \\
\hline berisikan permohonan pinjaman dan proses pembayaran pinjaman \\
\hline berisikan rekap gaji yang diperoleh karyawan di perusahaan \\
\hline
\end{tabular}

\section{Gambar 4. Menu-Menu yang Terdapat pada Website Karyawan}

Hasil validasi SIPAMIGA oleh ahli materi, ahli media, dan pengguna uji coba kelompok kecil secara keseluruhan disajikan dalam Tabel 1. 
Jurnal Ekonomi, Bisnis dan Pendidikan, 1(4), 2021, 405-412

Tabel 1. Data Hasil Validasi Keseluruhan

\begin{tabular}{clcc}
\hline No & \multicolumn{1}{c}{ Validasi } & Persentase & Kriteria Validitas \\
\hline 1. & Ahli Materi & $96,00 \%$ & Sangat Valid \\
2. & Ahli Media & $94,00 \%$ & Sangat Valid \\
3. & Pengguna sebagai Administrator & $94,50 \%$ & Sangat Valid \\
4. & Pengguna sebagai Karyawan & $94,00 \%$ & Sangat Valid \\
& & $94,62 \%$ & Sata-rata
\end{tabular}

Table used by permission (CNirmala, Rari Nitya. 2020. Data hasil validasi keseluruhan

Berdasarkan Tabel 1, diketahui rata-rata persentase validasi secara keseluruhan sebesar 94,62\%, sehingga dapat disimpulkan bahwa sistem kearsipan gaji yang dikembangkan peneliti yakni SIPAMIGA, dinyatakan 'Sangat Valid',layak dan efektif digunakan dalam Kearsipan Gaji di PT. Subur Jaya Prima.

Contoh sistem kearsipan maupun sistem administrasi gaji yang sudah dikembangkan tidak semata hanya satu proses saja seperti pada penelitian sebelumnya (Rachma, 2015), (Latif \& Pratama, 2015), (Rifauddin, 2016),(Priyambodo, Novamizanti, \& Usman, 2020),(Hakim, Tekat, Waluyo, \& Hutasoit, 2020). sistem kearsipan dan administrasi gaji elektronik ini mengkombinasi antara sistem kearsipan dan administrasi gaji yang otomatis serta penyimpanan data yang otomatis, sehingga pengguna dapat terbantu dalam proses kearsipan dan pengolahan administrasi gaji dengan lebih cepat dan tepat melalui pembaruan sistem yang belum ada sebelumnya.

Hasil penelitian ini relevan dengan penelitian yang dilakukan oleh sejumlah peneliti diantaranya oleh (Villarama, 2017) yang menunjukan hasil bahwa Sistem yang dikembangkan memuat proses absensi dan penggajian secara otomatis yang dapat membantu mempercepat proses penggajian karyawan. Manfaat penggunaan juga dibuktikan oleh (Adrila \& Dharmawati, 2016) yang mengungkapkan bahwa kearsipan elektronik mampu meminimalisir kesalahan pencarian maupun penyimpanan arsip bagi suatu perusahaan. Begitu juga penelitian yang dilakukan oleh (Luckyano, 2019) mengungkapkan bahwa sistem penggajian elektronik mampu mengurangi kesalahan-kesalahan penulisan yang dapat merugikan pihak perusahaan.

\section{Simpulan}

Penelitian dan pengembangan ini menghasilkan sistem Kearsipan Gaji berbasis Website Dinamis yang layak dan efektif untuk digunakan berdasarkan hasil validasi Ahli Media, Ahli Materi serta pengguna di PT. Subur Jaya Prima. Sistem Kearsipan Gaji ini bernama SIPAMIGA. Sistem Kearsipan Administrasi Gaji pada penelitian ini telah dinyatakan 'Sangat Valid', dan layak digunakan berdasarkan validasi oleh ahli materi dan ahli media. Selain itu, sistem kearsipan administrasi gaji ini telah terbukti efektif untuk digunakan pada uji coba kelompok kecil yaitu karyawan PT. Subur Jaya prima yang terdiri dari pengguna sebagai administrator dan pengguna sebagai karyawan berdasarkan kebutuhan dinilai dari beberapa faktor yaitu faktor ketertarikan, kemudahan, kemanfaatan, dan keamanan. Sistem ini memuat proses kearsipan mulai dari pencatatan sampai dengan penyimpanan serta memuat proses administrasi gaji yaitu presensi, penulisan sampai pencetakan slip gaji dan pinjaman karyawan.

SIPAMIGA ini hanya berfokus pada pengolahan arsip administrasi gaji dan penggunaan dapat dijalankan berbasis online maupun offline namun berbasis offline terbatas pada satu 
jaringan di ruang tertentu, sehingga diharapkan peneliti selanjutnya untuk mengembangkan sistem kearsipan administrasi gaji dapat diakses offline dan menyajikan menu terkait administrasi gaji yang lebih lengkap.

\section{Ucapan Terima Kasih}

Penulis mengucapkan terimakasih kepada Universitas Negeri Malang dan PT. Subur Jaya Prima yang telah memfasilitasi dan memberi izin kepada peneliti untuk melakukan kegiatan penelitian dan pengembangan ini

\section{Daftar Rujukan}

Adrila, F., \& Dharmawati, D. M. (2016). Electronic Filing System berbasis Electronic Leitz Ordner di PT. Taspen. Jurnal Utilitas, 2(1), 46-53.

Artamonov, A., Ionkina, K., Tretyakov, E., \& Timofeev, A. (2018). Electronic document processing operating map development for the implementation of the data management system in a scientific organization. Procedia Computer Science, 145, 248-253. doi: 10.1016/j.procs.2018.11.053

Ayaz, A., \& Yanartaş, M. (2020). An analysis on the unified theory of acceptance and use of technology theory (UTAUT): Acceptance of electronic document management system (EDMS). Computers in Human Behavior Reports, 2, 100032. doi: 10.1016/j.chbr.2020.100032

Bagir, M., \& Rahmadian, J. (2016). Rancang Bangun Sistem Informasi Penggajian (ePAYROLL) Studi Kasus: STTI NIIT I-TECH. SESINDO 2016, 2016.

Barter, L., \& Cooper, C. L. (2021). The impact of electronic medical record system implementation on HCV screening and continuum of care: A systematic review. Annals of Hepatology, 24, 100322. doi: 10.1016/j.aohep.2021.100322

Casey, M. H., Turner, B., Edwards, L., \& Williams, M. (2020). Improving Efficiency Using Electronic Medical Record Rounding Report \& Sign-Out Report. Journal of Pediatric Health Care, 34(6), 535-541. doi: 10.1016/j.pedhc.2020.06.001

Engelman, A., Enkvist, C., \& Pettersson, K. (2019). A FAIR archive based on the CERIF model. Procedia Computer Science, 146, 190-200. doi: 10.1016/j.procs.2019.01.076

Filchev, L., Pashova, L., Kolev, V., \& Frye, S. (2020). Surveys, Catalogues, Databases/Archives, and State-of-theArt Methods for Geoscience Data Processing. In Knowledge Discovery in Big Data from Astronomy and Earth Observation (pp. 103-136). Elsevier. doi: 10.1016/B978-0-12-819154- 5.00016-3

Grahl, M., Bluhm, T., Grün, M., Hennig, C., Holtz, A., Krom, J. G., ... Werner, A. (2017). Archive WEB API: A web service for the experiment data archive of Wendelstein 7-X. Fusion Engineering andDesign, 123, 10151019. doi: 10.1016/j.fusengdes.2017.02.047

Hakim, Z., Waluyo, E. T. B., \& Hutasoit, A. R. (2020). Sistem Informasi Penggajian Guru Menggunakan Aplikasi Web pada SD Markus Tangerang. JURNAL SISFOTEK GLOBAL, 10(2).

Holgersson, M., \& Aaboen, L. (2019). A literature review of intellectual property management in technology transfer offices: From appropriation to utilization. Technology in Society, 59, 101132. doi: 10.1016/j.techsoc.2019.04.008

Jacobs, M., Boersma, L. J., Swart, R., Mannens, R., Reymen, B., Körver, F., ... Dekker, A. (2019). Electronic Health Record implementation in a large academic radiotherapy department: Temporarily disruptions but long-term benefits. International Journal of Medical Informatics, 129, 342-348. doi: 10.1016/j.ijmedinf.2019.07.008

Jedwab, R. M., Chalmers, C., Dobroff, N., \& Redley, B. (2019). Measuring nursing benefits of an electronic medical record system: A scoping review. Collegian, 26(5), 562-582. doi: 10.1016/j.colegn.2019.01.003

Jervis, M., \& Masoodian, M. (2014). How do people attempt to integrate the management of their paper and electronic documents? Aslib Journal of Information Management, 66(2), 134-155. doi: 10.1108/AJIM01-2013-0007

Kaneko, K., Onozuka, D., Shibuta, H., \& Hagihara, A. (2018). Impact of electronic medical records (EMRs) on hospital productivity in Japan. International journal of medical informatics, 118, 36-43. 
Klapita, V. (2021). Implementation of Electronic Data Interchange as a Method of Communication Between Customers and Transport Company. Transportation Research Procedia, 53, 174-179. doi: 10.1016/j.trpro.2021.02.023

Latifah, F., \& Pratama, A. W. (2015). Perancangan Sistem Informasi Manajemen Arsip Elektronik (e-Arsip) Berbasis Microsoft Access pada PT Hi-Test. Jurnal Akuntansi, Ekonomi dan Manajemen Bisnis, 3(1), 2131.

Lee, H., Aydin, N., Choi, Y., Lekhavat, S., \& Irani, Z. (2018). A decision support system for vessel speed decision in maritime logistics using weather archive big data. Computers \& Operations Research, 98, 330-342. doi: 10.1016/j.cor.2017.06.005

Liu, B. J., \& Huang, H. K. (2020). Picture archiving and communication systems and electronicmedical records for the healthcare enterprise. In Biomedical Information Technology (pp. 105- 164). Elsevier. doi: 10.1016/B978-0-12-816034-3.00004-3

Luckyano, R. B. (2019). TA: Penerapan Text Mining untuk Visualisasi Fluktuasi Harga Komoditas Pangan (Studi Kasus Twitter, Liputan 6, Detikcom) (Doctoral dissertation, Institut Bisnis dan Informatika Stikom Surabaya).

Mastumasari, I., Wasiti, \& Sulistyaningsih. (2017). Improving Learning Outcomes in Office Automation Subjects Through Development of Video-Based Media Learning Operating Microsoft Publisher 2010. JPBM (Jurnal Pendidikan Bisnis Dan Manajemen), 3(1), 55-64. doi: 10.17977/um003v3i12017p055

Mulyani, S., Sidik, A., \& Sari, A. (2020). Sistem Informasi Aplikasi Penggajian Karyawan Berbasis Web Pada PT Panca Cipta Abadi. JURNAL SISFOTEK GLOBAL, 10(2).

Perdanakusuma, D., Puspitasari, W., \& Saputra, M. (2020). Utilizing Open ERP for Creating Medical Record Management System in Smart Hospital: A Case Study. 2020 IEEE International Conference on Industry 4.0, Artificial Intelligence, and Communications Technology (IAICT), 1-7. Bali, Indonesia: IEEE. doi: 10.1109/IAICT50021.2020.9172029

Polat, Z. A., \& Alkan, M. (2018). Design and implementation of a LADM-based external archive data model for land registry and cadastre transactions in Turkey: A case study of municipality. Land Use Policy, 77, 249-266. doi: 10.1016/j.landusepol.2018.05.010

Priyambodo, A., Novamizanti, L., \& Usman, K. (2020). Implementasi QR Code Berbasis Android padaSistem Presensi. Jurnal Teknologi Informasi dan Ilmu Komputer, 7(5), 1011. doi: 10.25126/jtiik.2020722337

Putra, W. I., \& Nelisa, M. (2020). Pengelolaan Arsip Elektronik di Unit Kearsipan PT Semen Padang. Ilmu Informasi Perpustakaan dan Kearsipan, 8(2), 39-47.

Rachma, E. A. (2015). Penggunaan Aplikasi e-Surat SIKD (Sistem Informasi Kearsipan Dinamis) Dalam Pengelolaan Arsip Elektronik Untuk Mendukung E-Government Di Badan Arsip Dan Perpustakaan Kota Surabaya. Jurnal Pendidikan Administrasi Perkantoran (JPAP), 3(3).

Rifauddin, M. (2016). Pengelolaan arsip elektronik berbasis teknologi. Khizanah al-Hikmah: Jurnal Ilmu Perpustakaan, Informasi, dan Kearsipan, 4(2), 168-178.

Santipantakis, G. M., Glenis, A., Patroumpas, K., Vlachou, A., Doulkeridis, C., Vouros, G. A., ... Theodoridis, Y. (2020). SPARTAN: Semantic integration of big spatio-temporal data from streaming and archival sources. Future Generation Computer Systems, 110, 540-555. doi: 10.1016/j.future.2018.07.007

Shirai, T., \& Kiritani, K. (2021). A study on the problem of business IT system utilization in Japanese companies Construction of non-utilization model according to business characteristics of Japanese companies-. Procedia Computer Science, 181, 285-293. doi: 10.1016/j.procs.2021.01.148

Sievers, F., Reil, H., Rimbeck, M., Stumpf-Wollersheim, J., \& Leyer, M. (2021). Empowering employeesin industrial organizations with IoT in their daily operations. Computers in Industry, 129, 103445. doi: 10.1016/j.compind.2021.103445

Simangunsong, A. (2018). Sistem Informasi Pengarsipan Dokumen Berbasis Web. Jurnal Mantik Penusa, 2(1).

Sun, T. (2020). Mining and utilization of special information for archives management based on 5G network and Internet of Things. Microprocessors and Microsystems, 103410. doi: 10.1016/j.micpro.2020.103410

Usman, M., \& Qamar, U. (2020). Secure Electronic Medical Records Storage and Sharing UsingBlockchain Technology. Procedia Computer Science, 174, 321-327. doi: 10.1016/j.procs.2020.06.093

Villarama, J. D. A., Gernale, J. P. R. O., Ocampo, D. A. N., \& Villaverde, J. F. (2017, December). Wireless biometrie attendance management and payroll system. In 2017IEEE 9th International Conference on Humanoid, 
Jurnal Ekonomi, Bisnis dan Pendidikan, 1(4), 2021, 405-412

Nanotechnology, Information Technology, Communication and Control, Environment and Management (HNICEM) (pp. 1-5). IEEE.

Zheng, W., Wang, Y., Zhang, M., Wu, F., \& Yang, Z. (2020). A full stack data acquisition, archive and access solution for J-TEXT based on web technologies. Fusion Engineering and Design, 155, 111450. doi: 10.1016/j.fusengdes.2019.111450 